\title{
ELECTROMECHANICAL AND THERMOMECHANICAL STRESS ANALYSIS OF THE TOROIDAL FIELD MAGNET SYSTEM IN SINGLE TURN IGNITION TOKAMAKS
}

\author{
K.T. Hsieh, W.F. Weldon, and M.D. Werst \\ Center for Electromechanics \\ The University of Texas at Austin \\ 10100 Burnet Rd., Bldg. 133 \\ Austin, TX 78728-4497
}

(512) 471-4496

\author{
E. Montalvo and R. Carrera \\ Center for Fusion Engineering \\ The University of Texas at Austin \\ Austin, TX 78712 \\ (512) $471-6148$
}

\begin{abstract}
The Texas fusion ignition experiment (IGNITEX) device is a $20 \mathrm{~T}$ single turn coil tokamak designed to produce and control an ignited plasma using ohmic heating alone. As a baseline design, IGNITEX has a $1.5 \mathrm{~m}$ major radius and operates at a toroidal field (TF) of $20 \mathrm{~T}$ on-axis. The small version of IGNITEX $(R=1.2 \mathrm{~m})$ represents the smallest, low cost experiment that can produce fusion ignition under the saturated Neo-Alcator energy confinement scaling. The large version of IGNITEX $(\mathrm{R}=2.1 \mathrm{~m})$ represents the smallest experiment that can produce fusion ignition using the most pessimistic extrapolation of the Goldston scaling in L-mode. The Ignition Technology Demonstration (ITD) program was initiated to design, build, and test the operation of a single turn, $20 \mathrm{~T}$, TF coil powered by an existing $9 \mathrm{MA}$, HPG power supply system. The ITD TF coil is a 0.06 scale of the IGNITEX and is now operating at the Center for Electromechanics at The University of Texas at Austin (CEM-UT). Data from the ITD experiment is used to confirm the complex computer model utilized for the IGNITEX design and analysis. In this paper, feasibility of the TF magnets is evaluated based on the electromechanical and thermomechanical considerations.
\end{abstract}

\section{INTRODUCTION}

The concept of a single-turn tokamak as originally proposed by Rosenbluth, Weldon, and Woodson 1 , permits to envision a simple and low cost fusion ignition experiment. Because of the high magnetic field that can be produced in a single-turn tokamak, fusion ignition of a DT fuel is possible ohmically, far from marginal stability limits, and in the L-mode of operation. Conventional tokamak designs use multiturn coils. The windings are separated with insulation and structural material. Typical utilization factors of the inner leg region in the magnet coil are $50 \%$ in high field tokamaks. A single-turn tokamak allows for uti- lization factors of the inner leg close to unity and therefore the magnet system can be operated at the same current densities as in multiturn coils, but produce about twice the magnetic field.

The IGNITEX single-turn TF magnet is a compact system which is fabricated by stacking wedge-shaped copper alloy plates in a toroidal configuration, as shown in Figure 1. Axial preloading is utilized to neutralize the magnetic axial separation force and establish a rather uniform stress distribution in the inner leg. The entire magnet system is enclosed in an open cryostat and precooled to liquid nitrogen temperatures before a discharge. This permits the magnet to operate for a longer period without exceeding the material capability or degrading material properties. The system of tapered plates is maintained together by using thermally fitted radial rings. A "bucking cylinder" is used in the central hole to provide bucking support. The magnet plates are designed to operate in an optimized state of bucking and wedging at peak electromagnetic loading. An Inconel ${ }^{\circledR}$ ring-like terminal clamp provides both the

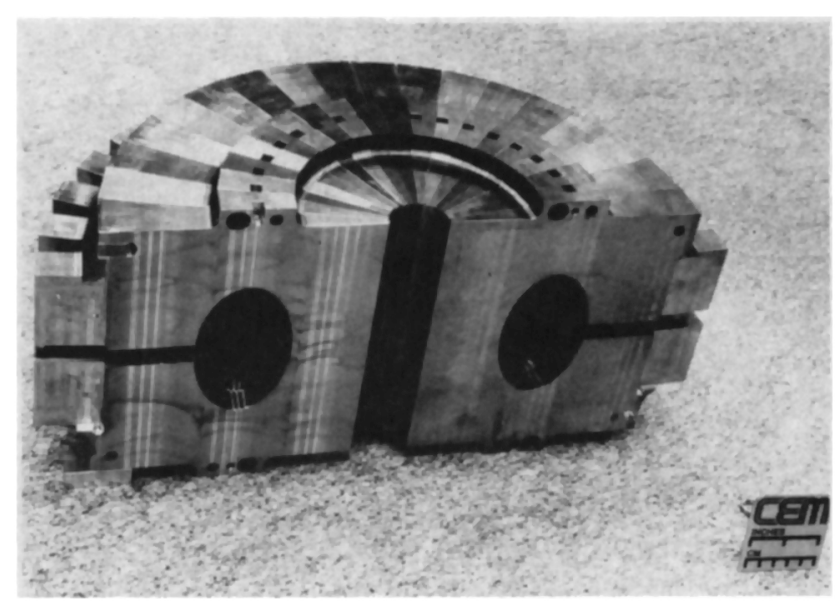

Figure 1. $180^{\circ}$ section of ITD TF magnet 
axial support for the outer leg and clamping pressure for the electrical joint between the TF coil terminals and the buswork, as shown in Figure 2. Physics considerations that motivate the definition of the large and small versions of the IGNITEX experiment are addressed in references 2-3. The ITD program at CEM-UT has the objective to design, build, and operate a full-torus, $20 \mathrm{~T}$, TF magnet prototype for IGNITEX, operated with homopolar generators (HPGs). 4 The scale of the ITD prototype is determined as the ratio of the current rating of the Balcones HPG system and the current requirement for IGNITEX (9 MA/150 MA). This high field magnet has already been operated to $15 \mathrm{~T} .4$ The empirical experience obtained in the ITD operation serves to check the validity of the complex electromechanical and thermomechanical analysis carried out in the design and analysis of the IGNITEX device.

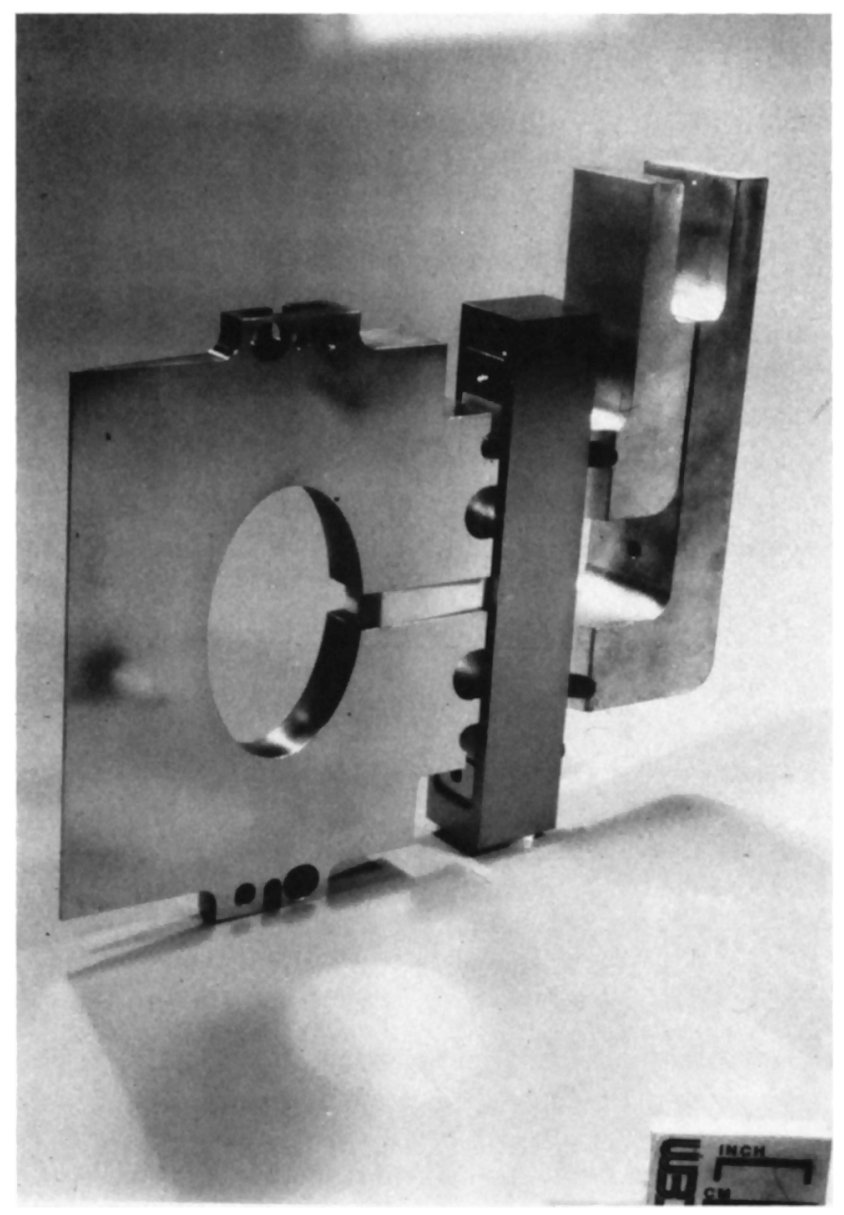

Figure 2. Single ITD TF magnet plate with terminals and terminal clamps

\section{ELECTROMECHANICAL ANALYSIS OF THE TOROIDAL FIELD MAGNET}

The TF magnet is exposed to severe magnetic and thermal loading due to the high magnetic field and long current profile. An optimum single turn TF coil design is possible utilizing a sophisticated finite element program (TEXCOR 5 ). This numerical program solves a set of coupled electrical circuit, magnetic diffusion, and thermal diffusion equations with temperature dependent properties. The calculation predicts magnetic loading and temperature distribution within the magnet structure. A stress analysis of the magnet subject to the body force density and the thermal loading obtained from the electromagnetic calculation is performed by using a three dimensional (3-D) finite element code (ABAQUS6), A full electrothermomechanical analysis has been conducted on the TF magnets of the ITD and the small and large versions of IGNITEX by using TEXCOR and ABAQUS. These evaluations are described in the following sections.

\section{PARAMETERS AND CONFIGURATIONS OF THE TOROIDAL FIELD MAGNET SYSTEM}

The TF magnet parameters for configurations considered here are listed in Table 1. Current in the small IGNITEX version ramps up in $4 \mathrm{~s}$, has $2 \mathrm{~s}$ flat top and shuts down in $2 \mathrm{~s}$. For the large IGNITEX version, current rises in $8 \mathrm{~s}$, maintains at maximum current for $6 \mathrm{~s}$, and shuts down in $4 \mathrm{~s}$. Due to the inductance mismatch between the magnet and the existing power supply system (the 9 MA Balcones HPG system), the prototype is subjected to a longer current pulse than that scaled for 0.06 scale magnet (Fig. 3). Selection of the magnet material was based on trade-offs between electrical conductivity, yield strength, material stability and plate thickness. ${ }^{7}$ Beryllium copper (C17510) was chosen as the conductor material for the prototype TF coil. Produced by Brush Wellman, Inc., Brush Alloy \#3 exhibits a room temperature electrical conductivity of $64 \%$ IACS and a $0.2 \%$ yield strength of $108 \mathrm{ksi}$. Electrical conductivity of Brush Alloy \#3 improves by a factor of 2.3 at liquid nitrogen temperature.

A detailed parametric study was performed to study the effects of size and material of the bucking cylinder and the optimum position and magnitude of the axial preloading. 5 An optimum preloading configuration is one producing uniform stress distribution throughout the inner leg area of a magnet. A reduced bucking cylinder size reduces peak temperatures and stresses in the inner leg region. This is attributed to better current pene- 
Table 1. Parameters for the $20 \mathrm{~T}$, single turn TF coil

\begin{tabular}{|c|c|c|c|}
\hline PARAMETERS/SCALE & 0.06 & SMALL & LARGE \\
\hline B (T) & 20 & 20 & 20 \\
TF major radius R (m) & 0.09 & 1.2 & 2.1 \\
I TF Peak (MA) & 9 & 120 & 210 \\
Pulse width (flat top) & $103 \mathrm{~ms}$ & $8 \mathrm{~s}(2 \mathrm{~s})$ & $18 \mathrm{~s}(6 \mathrm{~s})$ \\
TF minor radius $\mathrm{r}(\mathrm{cm})$ & 3 & 45 & 78 \\
Bucking cylinder radius $(\mathrm{cm})$ & 1.2 & 5 & 5 \\
Tf Aspect Ratio & 3 & 2.67 & 2.69 \\
\hline
\end{tabular}

4501.0058

tration and a larger wedging area for the magnetic and thermal loads to react. Thus, the magnet design leans toward the pro-wedging support mechanism. Due to a stack-up of flatness tolerances, a magnet purely "bucked" would result in stresses twice as high as in pure wedging. In order to assure the magnet is not in pure bucking, the detailed design of bucking cylinder is crucial.

The radial gap between the magnet and the bucking cylinder is sized to allow the inward magnetic radial force to close the stack-up tolerance of the magnet without contacting the bucking cylinder. On the other hand, the radial gap should be sized to assure that the bucking cylinder contacts the magnet and to provide bucking support during the high magnetic load period. Concentricity is maintained between the bucking cylinder and the TF coil by use of a low stiffness material. The radial gap normally is chosen to be the average value of the radial displacement due to stack-up

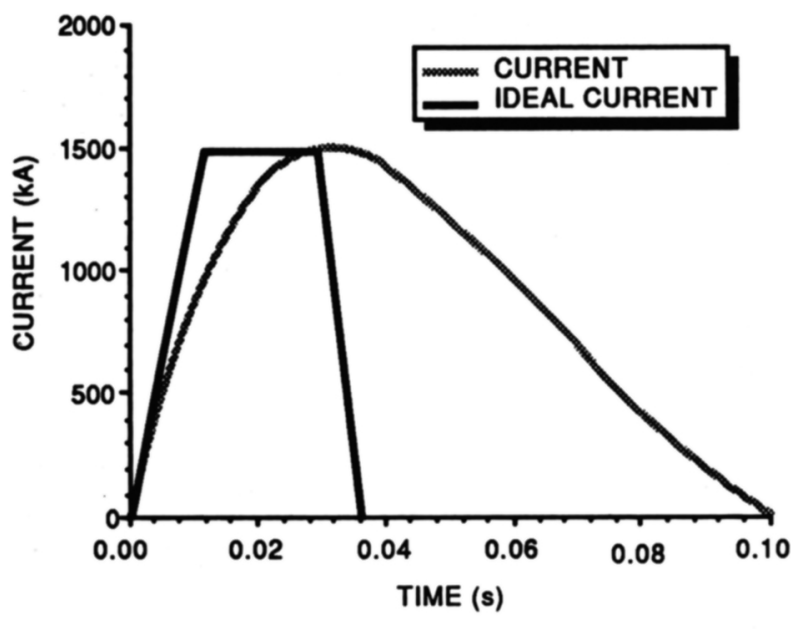

4501.0038

Figure 3. ITD current profiles -- simulated and ideal tolerance and total radial displacement for pure wedging. The stack-up tolerance can be verified experimentally.

In regard to material selection for the bucking cylinder, three properties are considered: stiffness, strength and thermal expansion coefficient. Three materials; beryllium copper, stainless steel, and tungsten, were chosen based on their relative values for these properties. The resulting maximum Mises' stresses values are insensitive to which of these materials are used. Consequently, beryllium copper was chosen for the bucking cylinder simply because it eliminates thermal expansion mismatch during the precooling of the magnet to liquid nitrogen temperature.

The design of the TF magnets in the IGNITEX versions is based on the engineering aspects. A beryllium copper TF magnet with a suitable size of $\mathrm{BeCu}$ bucking cylinder and an axial preloading producing uniform stresses in inner leg represents the optimum configuration.

\section{NUMERICAL MODELS AND SIMULATIONS}

The out-of-plane loads in IGNITEX devices due to interaction between toroidal current and poloidal field are insignificant because internal PF coils confine most of flux inside the plasma bore and, furthermore, the toroidal current and poloidal field trace similar contours. Only in-plane loads are applied in the TF stress analsyis. Because of the top/bottom symmetry, only the upper half of the magnet needs to be modeled. An adiabatic process is assumed in the electromagnetic analysis. No heat is conducted out along the boundary. The resulting temperatures at the ID and OD of the inner leg and the typical magnetic load profiles are shown in Figures 4 through 7 . These body forces and temperatures are used in the stress analysis of magnet systems. A $3-\mathrm{D}, 10^{\circ}$ sector model, which

Table 2. Summary of results of IGNITEX toroidal coils

\begin{tabular}{|c|c|c|c|}
\hline PARAMETERS/SCALE & 0.06 & SMALL & LARGE \\
\hline Sep. Force (MN) & 12 & 2250 & 6800 \\
Preload Req. (Tons) & 420 & 110000 & 320000 \\
Mises' Stress (ksi) & & & \\
at max. load & 87 & 93 & 93 \\
at max. temp. & 90 & $50^{*}$ & $58^{*}$ \\
Highest Temp. (c) & 187 & 154 & 158 \\
\hline
\end{tabular}




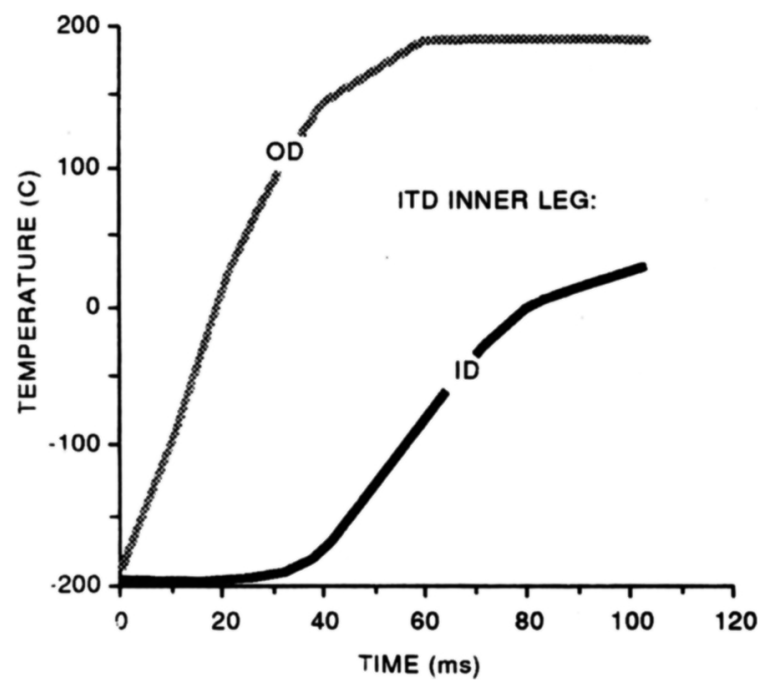

4501.0064

Figure 4. Temperature at inner and outer diameter of ITD inner leg

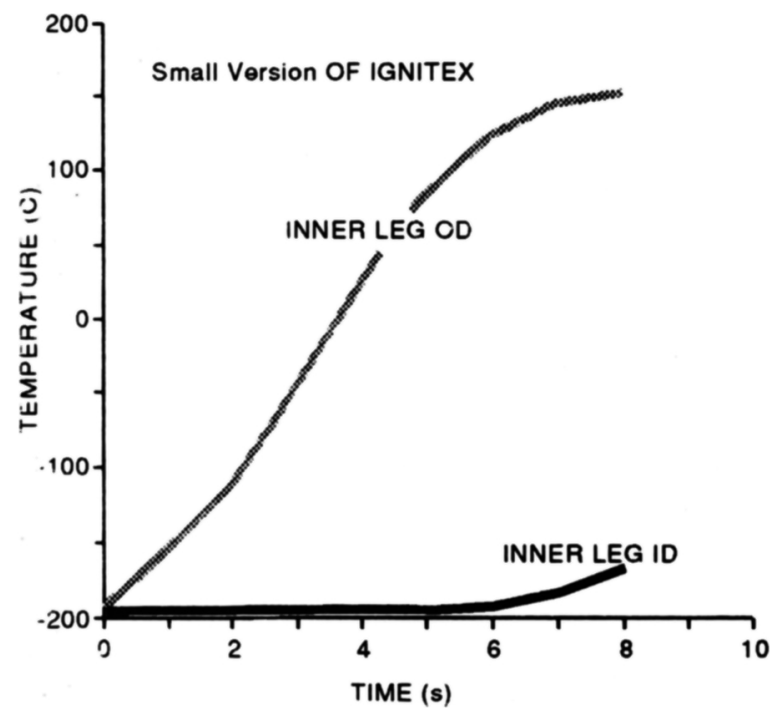

4501.0063

Figure 5. Temperature at inner and outer diameter of inner leg of small version of IGNITEX

consists of two halves of a single plate and a gap (due to flatness tolerance), is constructed for the stress analysis. An elastic foundation representing an Inconel ${ }^{\circledR}$ clamp is applied along the upper face of the terminal lead. The deformed shapes and typical Mises' stress contour are shown in Figures 8 to 10.

A summary of separation force, preload requirement, maximum Mises' stress, and highest temperature for the three systems is listed in Table 2. It is desirable to know how the three criti-

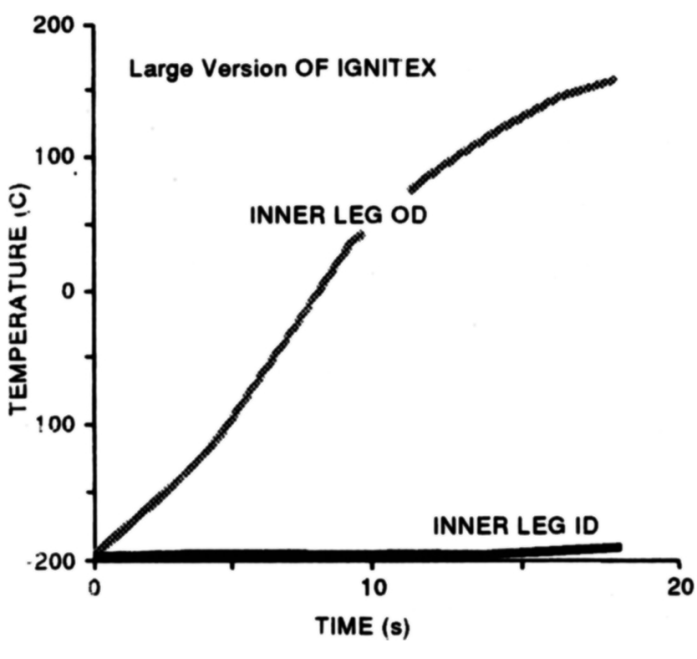

4501.0065

Figure 6. Temperature at inner and outer diameter of inner leg of large version of IGNITEX

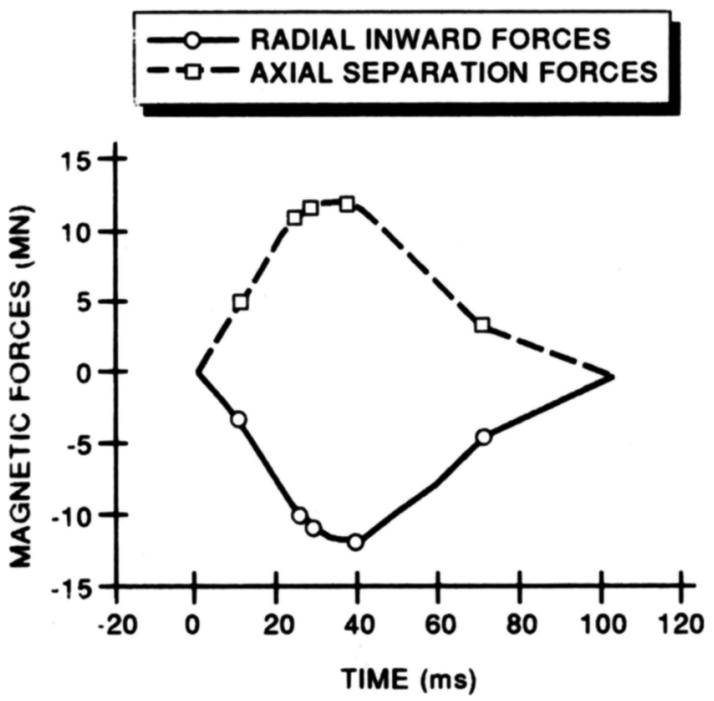

4501.0061

Figure 7. Typical magnetic forces

cal elements of precooling, bucking, and axial preloading affect the capacity of the magnet. Table 3 gives a summary of the maximum capacity of the prototype magnet under various circumstances. Without axial preloading, a precooled, bucked ITD magnet can produce an on-axis toroidal field of $18 \mathrm{~T}$.

In comparison with ITD test data $^{4}$, axial strain at the outer diameter of the inner leg during the preload process agrees well with experimental 


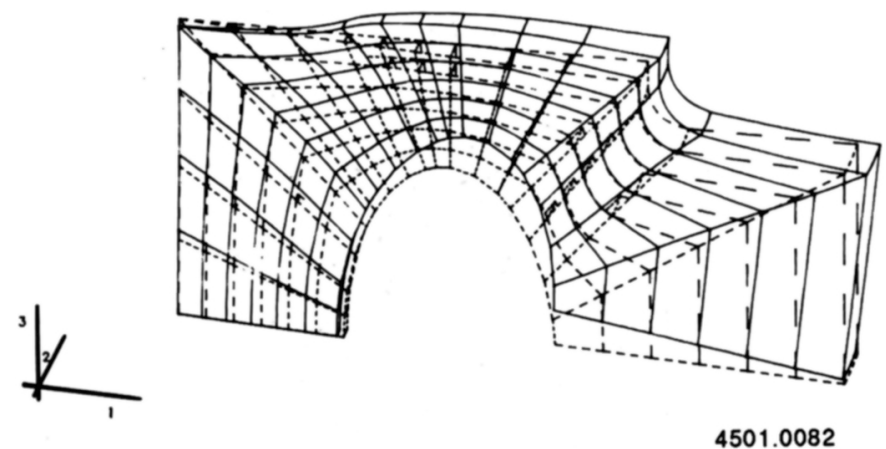

Figure 8. Deformed shape of small version of IGNITEX

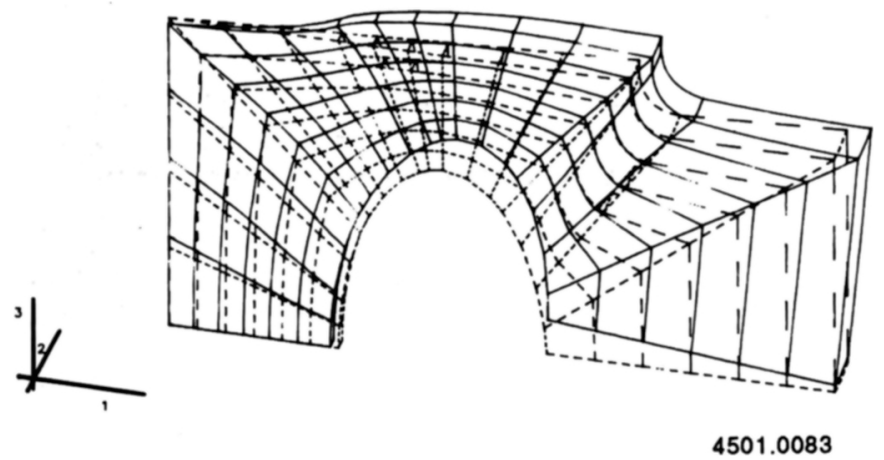

Figure 9. Deformed shape of large version of IGNITEX

data. The predicted temperatures are higher than the measured values. Deviation becomes larger, when the toroidal field is higher. This may be explained by the conservative adiabatic assumption. The peak axial strains during the discharge exhibit the same trend as temperatures. It is believed that this phenomena can be also attributed to the prediction of higher than experimentally observed temperatures in the magnet. This results in noticeably higher predicted thermal strains and therefore higher prediction of axial strains. Further comparison with measured data will be pursued during high current (field $>15 \mathrm{~T}$ ) test.

\section{CONCLUSION}

Analytical computer model's predictions of strains, temperature rises and field levels agree well with actual measurements. This validates the
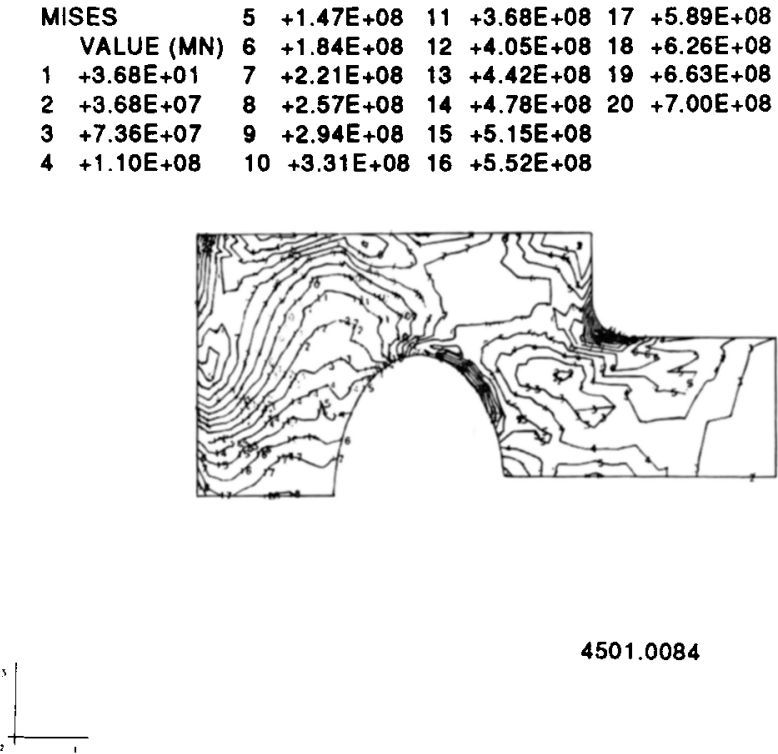

4501.0084

Figure 10. Typical von Mises' stress contour

Table 3. Prototype test mode

\begin{tabular}{|c|c|c|c|c|c|}
\hline \multicolumn{7}{|c|}{ PROTOTYPE TEST MODES } \\
\hline & CASE & CASE 2 & CASE 3 & CASE 4 & CASE 5 \\
\hline PRECOOL & NO & YES & YES & YES & YES \\
PRELOAD & NO & NO & NO & YES & YES \\
BUCKING CYLINDER & NO & NO & YES & NO & YES \\
DLANED HIGHEST FIELD (T) & 10 & 14 & & & \\
HIGHEST TEMP (c) & 131 & 733 & & & \\
MAXIMUM MISES STRESS (kEi) & 33 & 65 & & & \\
MAXIMUM ALLOWABLE FIELD (T) & 14 & 17 & 18 & 19 & 20 \\
HIGHEST TEMPERATURE (O) & 238 & 80.7 & 114 & 151 & 187 \\
MAXIMUM MISES' STRESS (kSi) & 66 & 97 & 101 & 90 & 90 \\
\hline
\end{tabular}

4501.0060

complex electrothermomechanical model used in the calculation. Based on an electromechanical analysis, the ITD, the small version and large version of the IGNITEX experiment have the ability to generate and maintain the high toroidal magnetic field in the necessary geometry required to produce fusion ignition by ohmic heating alone.

\section{ACKNOWLEDGEMENTS}

This work is sponsored by the Texas Advanced Technology Program and the Texas Atomic Energy Research Foundation.

\section{REFERENCES}

1. M.N. ROSENBLUTH, W.F. WELDON and H.H. WOODSON, "Basic Design Report of the Fusion Ignition Experiment (IGNITEX)," presented in Texas Atomic Energy Foundation Project Progress Report, March 1987. 
2. E. MONTALVO, R. CARRERA, G. Y. FU, J. F. HELTON, L. M. HIVELY, H. C. HOWE, G. H. MILEY, C. A. ORDONEZ, M. N. ROSENBLUTH, D. J. SIGMAR, S. TAMOR, J. W. VAN DAM, and H. XIAO, "Fusion Physics Study of the IGNITEX Experiment," 13th International Symposium on Fusion Engineering, Knoxville, TN, (October, 1989).

3. E. MONTALVO, B. R. SHI, R. CARRERA, G. Y. FU, Z. GUO, R. HAZLTINE, L. HIVELY, G. MILEY, M. N. ROSENBLUTH, K. TANI, J. W. VAN DAM, and H. XIAO, "Plasma Behavior Throughout the Discharge of an Ohmically Heated Ignition Tokamak Experiment," Ninth Topical Meeting on the Technology of Fusion Energy, Oak Brook, IL, October, 1990).

4. M. D. WERST, G. W. BRUNSON, K. T. HSIEH, R. L. SLEDGE, D. J. WEHRLEN, and W. F. WELDON, "Magnet Technology Demonstration for an Ignition Single-Turn Tokamak," Ninth Topical Meeting on the Technology of Fusion Energy, Oak Brook, IL, (October, 1990).

5. K. T. HSIEH, M. D. DRIGA, W. F. WELDON, and M. D. WERST "Electromechanical Analysis of a Prototype 20 Tesla, Single-Turn, Toroidal Field Coil for IGNITEX", 13th International Symposium on Fusion Engineering, Knoxville, TN, (October, 1989).

6. ABAQUS; A commercial general purpose finite telement program on solid mechanics is developed by Hibbitt, Karlsson \& Sorensen, Inc.

7. M.D. WERST, G.W. BRUNSON, M.D. DRIGA, K.T. HSIEH, R.L. SLEDGE and W.F. WELDON, 'Design of a Prototype 20 Tesla, Single Turn, Toroidal Field Coil for the Fusion Ignition Experiment (IGNITEX)," 13th Symposium on Fusion Engineering. Knoxville, TN, October, 1989. 